\title{
The effect of transversus abdominis plane block on the chronic pain after colorectal surgery: a retrospective cohort study
}

\author{
Zi-Ye Pan, Zhong-Hua Hu, Fan Zhang, Wen-Xiu Xie, Yong-Zhong Tang ${ }^{*}$ and Qin Liao* (D)
}

\begin{abstract}
Background: Chronic postsurgical pain (CPSP) is common and would reduce the quality of life of patients. Transversus abdominal plane (TAP) block has been widely used in lower abdominal surgery and many researches demonstrated that it could improve acute postsurgical pain. We aim to determine whether TAP block could improve chronic postoperative pain at 3 months and 6 months after colorectal surgery.
\end{abstract}

Methods: A total of 307 patients received selective colorectal surgery under general anesthesia between January, 2015 and January, 2019 in a single university hospital were included: 128 patients received TAP block combined with patient-controlled intravenous analgesia (PCIA) for postsurgical analgesia (group TP) and 179 only administrated with PCIA (group P). Main outcome was the NRS score of pain at 3 months after colorectal surgery. The data was analyzed by two-way repeated measures anova and the chi-square test.

Results: The NRS score at rest and during movement was decreased significantly at $24 \mathrm{~h}$ after surgery (rest NRS $1.07 \pm$ 1.34 vs $1.65 \pm 1.67$, movement NRS $3.00 \pm 1.45$ vs $3.65 \pm 1.89$; all $P=0.003$ ) in group TP than those of group P. There was no significant difference of NRS score at $48 \mathrm{~h}$ after surgery $(P>0.05)$. At 3 months after surgery, the NRS score during movement was also lower in group TP than that in group $P(0.59 \pm 1.23$ vs $0.92 \pm 1.65, P=0.045)$. There was no significant difference of NRS score at 6 months after surgery $(P>0.05)$. The prevalence of CPSP was 19.5\% (25/128) in group TP and 20.7\% (37/179) in group P at 3 months after surgery. $13.2 \%$ (17/128) of patients suffered from CPSP in group TP and 13.9\% (25/179) in group P at 6 months after surgery. Both at 3 months and 6 months after surgery, there was no statistical difference of the prevalence of CPSP between the two groups (all $P>0.05$ ).

Conclusions: TAP block reduced NRS during movement at 3 months after surgery but did not reduce the incidence of CPSP at 3 months and 6 months after selective colorectal surgery.

Keywords: Chronic postsurgical pain, Colorectal surgery, Transversus abdominal plane block, Analgesia

\section{Background}

Chronic postsurgical pain (CPSP) is defined by the International Association for the Study of Pain (IASP) as pain that develops after a surgical procedure and persists for at least 3 months after surgery, where all other causes of pain

\footnotetext{
* Correspondence: tangyongzhong@csu.edu.cn; xy3yyliaoqin@sina.com Department of Anesthesiology, The Third Xiangya Hospital of Central South University, Changsha 410013, Hunan, China
}

(e.g. infection, recurring malignancy) or pre-existing pain problems are excluded $[1,2]$. Few studies reported the prevalence of CPSP after colorectal surgery [3, 4]. A prospective study showed that $19 \%$ of patients underwent colorectal surgery reported CPSP at 6 months, $63 \%$ of which taking medication for their pain, 53\% of which were using opioids to manage their pain [3]. In another retrospective study, $17 \%$ of patients reported CPSP after

(c) The Author(s). 2020 Open Access This article is licensed under a Creative Commons Attribution 4.0 International License, which permits use, sharing, adaptation, distribution and reproduction in any medium or format, as long as you give appropriate credit to the original author(s) and the source, provide a link to the Creative Commons licence, and indicate if changes were made. The images or other third party material in this article are included in the article's Creative Commons licence, unless indicated otherwise in a credit line to the material. If material is not included in the article's Creative Commons licence and your intended use is not permitted by statutory regulation or exceeds the permitted use, you will need to obtain permission directly from the copyright holder. To view a copy of this licence, visit http://creativecommons.org/licenses/by/4.0/ The Creative Commons Public Domain Dedication waiver (http://creativecommons.org/publicdomain/zero/1.0/) applies to the data made available in this article, unless otherwise stated in a credit line to the data. 
laparoscopic colorectal surgery, 37\% of which suffering from severe pain (pain score $\geq 7$ ) [4]. CPSP has a negative impact on the quality of life, such as mood, sleep, walking ability, and normal work, so it is important to find out methods to reduce CPSP.

It was found that acute postoperative pain was an important risk factor of CPSP, [4-6] and many researches demonstrated that CPSP could be partly improved by optimizing perioperative pain management, including intravenous analgesia, epidural analgesia, paravertebral blocks and regional analgesia [7-9]. Transversus abdominis plane (TAP) block is an effective regional analgesia technique to reduce perioperative pain intensity, [10] especially combined with ultrasound-guided technique. TAP block is the injection of local anesthetics to neurofascial plane between internal oblique and transversus abdominis muscles aiming at blocking the neural afferents from the anterolateral abdominal wall (T7-L1) [11]. TAP block has been widely used in many abdominal operation, with a satisfactory duration of analgesic action for up to $24 \mathrm{~h}$ after surgery [10, 12-14]. Many studies confirmed that TAP block can improve acute postoperative pain, $[15,16]$ but whether TAP block can reduce chronic pain after colorectal surgery has been reported scarcely.

The main aim of our study was to evaluate whether TAP block could improve CPSP after colorectal surgery. We compared the NRS score of different time point for patients who had TAP block and PCIA with those patients without TAP block.

\section{Methods}

Our research was approved by the Ethics Committee of Third Xiangya Hospital, Central South University (No: 2019-S473). We reviewed the medical records of patients undertaking colorectal surgery at the third Xiangya hospital of Central South University from January, 2015 to January 2019. Eligibility criteria included patients who were over 18 years old, American Society of Anesthesiologists (ASA) status I-III, receiving selective colorectal surgery under general anesthesia and PCIA for postsurgical analgesia. Exclusion criteria were patients unable to communicate, wound infection after surgery, receiving a second operation.

\section{Study protocol}

On entering the surgery room, patients' vital signs were monitored by electrocardiogram, invasive arterial blood pressure, pulse oximetry and bispectral index. General anesthesia was induced with fentanyl $(4-6 \mu \mathrm{g} / \mathrm{kg})$ or sufentanil $(0.4-0.6 \mu \mathrm{g} / \mathrm{kg})$, propofol $(1.5-2 \mathrm{mg} / \mathrm{kg})$, midazolam $(2-3 \mathrm{mg})$, rocuronium $(1 \mathrm{mg} / \mathrm{kg})$ or cisatracurium besylate $(0.15-0.2 \mathrm{mg} / \mathrm{kg})$. Anesthesia was maintained both with intravenous infusion propofol 4 to $7 \mathrm{mg} / \mathrm{kg} / \mathrm{h}$, remifentanil 6 to $10 \mu \mathrm{g} / \mathrm{kg} / \mathrm{h}$, and inhalation of 1 to $2 \%$ sevoflurane. Fentanyl or sufentanil was used when signs of inadequate analgesia were evident intraoperatively such as increased heart rate or blood pressure. $0.05 \mathrm{mg} / \mathrm{kg}$ of cisatracurium was administered at 30-40 min intervals. All patients received $0.25 \mathrm{mg}$ palonosetron hydrochloride intravenously before suture.

For those patients who received TAP block, bilateral TAP block was performed by ultrasound (SonoSite EdgeII, American) before anesthesia induction. $40 \mathrm{ml}$ of $0.5 \%$ ropivacaine (AstraZneca AB, Sweden, $20 \mathrm{ml}$ each side) was injected into the transversus abdominis plane under real-time ultrasound guidance.

Postoperatively, electronic analgesic pump with wireless analgesic system was used for $48 \mathrm{~h}$ of PCIA (Renxian Medtech, Jiangsu). The PCIA pump was filled with sufentanil $150 \mu \mathrm{g}$, azasetron $10 \mathrm{mg}$, diluted to $150 \mathrm{ml}$ with $0.9 \%$ normal saline. It was programmed to give $1.5-2 \mathrm{ml} / \mathrm{h}$ background infusion with a $1.5-2 \mu \mathrm{g}$ bolus of sufentanil solution, with a 5 min lockout time. Patients were routinely informed that they could control the pain by pressing a self-controlled button to only slight pain. Pain was assessed twice a day at rest and during movement with an 11-point Numeric Rating Scale (NRS) $(0=$ no pain; $10=$ pain 'as bad as you can imagine') by the same nurse of acute pain service group within $48 \mathrm{~h}$ after operation.

After discharged from hospital, postoperative followup team contacted patients via telephone at 3 months and 6 months after operation to complete pain evaluation (NRS score and painful place).

\section{The data extraction}

Patients' data including patients' ASA status, sex, age at the time of operation, body mass index was extracted from medical records. Patients' information about surgical and anesthetic management such as anesthesia duration, surgery duration, perioperative opioid dose and pain scores was extracted from Anesthesia records. All patients were allocated to two groups: group TP were those patients who received TAP block and PCIA; and group $\mathrm{P}$ were those patients who only received PCIA.

\section{Statistical analysis}

In order to facilitate comparison, fentanyl $0.1 \mathrm{mg}$ was equivalent to sufentanil $0.01 \mathrm{mg}$. Considering that remifentanil is an ultra-short-acting opioid, we analyzed it separately. Opioid usage was analyzed with the unpaired $\mathrm{t}$-test between two groups. Two-way repeated measures anova was used for NRS scores of $24 \mathrm{~h}, 48 \mathrm{~h}, 3$ months and 6 months after surgery. The chi-square test was used for comparisons of categorical data. Quantitative data were expressed as mean $\pm \mathrm{SD}$ and categorical variables as percentages. Data were analyzed with the SPSS 


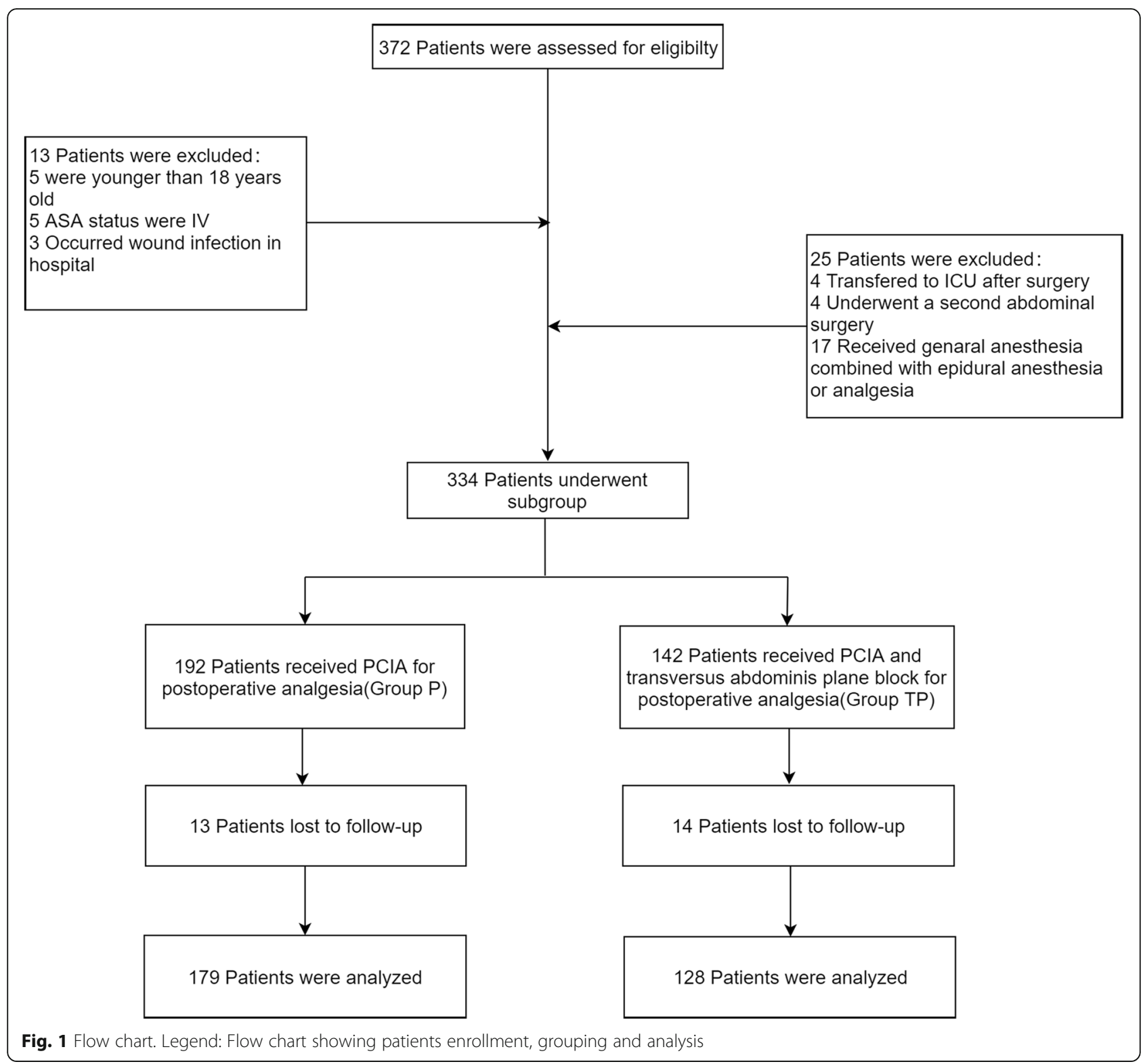

software version 22.0 (SPSS Inc., Chicago, IL). Significance was determined at $\mathrm{P}<0.05$.

\section{Patient and public involvement}

Patients and the public were not involved in planning, design, or interpretation of the study. The study involved examination of existing claims data and no participants were recruited for this analysis. This research was done without patient involvement. Patients were not invited to comment on the study design and were not consulted to develop patient relevant outcomes or interpret the results. Patients were not invited to contribute to the writing or editing of this document for readability or accuracy.

\section{Results}

Three hundred-seventy-two patients were included in this study between January 2015 and January 2019. Thirty eight patients were excluded (5 patients were younger than 18 years, 5 patients' ASA status was IV, 3 patients occurred wound infection in hospital, 4 patients were transferred to ICU after surgery, 4 patients underwent a second abdominal operation, 17 patients received general anesthesia combined with epidural anesthesia or analgesia). Three hundred-thirty-four patients meeting the selection criteria were reviewed (group $P=192$; group TP $=142$ ). There were 13 patients lost to followup in group P and 14 patients in group TP. Finally, 307 
patients were enrolled for analysis. The participant flow chart of this study was presented in Fig. 1.

Patients' demographics, ASA status, duration of surgery and anesthesia, and operative method were similar between the two groups (Table 1).

Compared with group P, there was a significant reduction in intraoperative sufentanil usage in group TP ( $51.3 \pm 12.6$ vs $64.8 \pm 18.8, P=0.000$ ), while there was no significant difference in remifentanil usage between two groups $(P>0.05)$. But the postoperative requirement for sufentanil showed no significant difference at $24 \mathrm{~h}$ and $48 \mathrm{~h}$ between group TP and group P $(P=0.255, P=$ 0.300 , respectively) (Table 2 ).

The NRS score at rest and during movement was decreased significantly at $24 \mathrm{~h}$ after surgery (rest NRS $1.07 \pm$ 1.34 vs $1.65 \pm 1.67$, movement NRS $3.00 \pm 1.45$ vs $3.65 \pm$ 1.89; all $p=0.003$ ) in group TP than those of group P. but there was no significant difference of NRS score at rest and during movement at $48 \mathrm{~h}(p>0.05)$. At 3 months after surgery, the NRS score during movement was also lower in group TP than that in group P $(0.59 \pm 1.23$ vs $0.92 \pm$ $1.65, p=0.045)$. There was no significant difference of NRS score at 6 months after surgery (all $P>0.05$ ) (Fig. 2).

In time comparison, both in group TP and group $\mathrm{P}$, the effect of time on pain was statistically significant (all $P<0.001)$ and the degree of pain decreased with time (Fig. 2).

The prevalence of CPSP at 3 months and 6 months after surgery were summarized in Fig. 3. Among 307

Table 1 Patients' demographics and clinical characteristics

\begin{tabular}{|c|c|c|c|c|}
\hline & $\begin{array}{l}\text { Group P } \\
(n=179)\end{array}$ & $\begin{array}{l}\text { Group TP } \\
(n=128)\end{array}$ & $\begin{array}{l}\text { Total } \\
(n=307)\end{array}$ & $P$ \\
\hline \multicolumn{5}{|c|}{ Gender } \\
\hline Male & $79(44.1 \%)$ & $74(57.8 \%)$ & 153(49.8\%) & 0.734 \\
\hline Female & 100(55.9\%) & $54(42.2 \%)$ & $154(50.2 \%)$ & \\
\hline Age (years) & $57.8 \pm 11.8$ & $59.6 \pm 12.2$ & $58.6 \pm 12.0$ & 0.190 \\
\hline BMI $\left(\mathrm{kg} / \mathrm{m}^{2}\right)$ & $22.7 \pm 3.2$ & $22.3 \pm 2.8$ & $22.5 \pm 3.0$ & 0.284 \\
\hline \multicolumn{5}{|c|}{ ASA status } \\
\hline । & $1(0.6 \%)$ & $1(0.8 \%)$ & $2(0.7 \%)$ & 0.405 \\
\hline$\|$ & $102(57.0 \%)$ & $73(57.0 \%)$ & $175(57.0 \%)$ & \\
\hline III & $76(42.4 \%)$ & $54(42.2 \%)$ & $130(42.3 \%)$ & \\
\hline Surgery duration (hours) & $3.8 \pm 1.4$ & $3.9 \pm 1.0$ & $3.8 \pm 1.3$ & 0.671 \\
\hline Anesthesia duration (hours) & $5.5 \pm 1.4$ & $5.6 \pm 1.0$ & $5.5 \pm 1.3$ & 0.593 \\
\hline \multicolumn{5}{|c|}{ Operative Method } \\
\hline Open & $36(20.1 \%)$ & $16(12.5 \%)$ & $52(16.9 \%)$ & 0.080 \\
\hline Laparoscope & 143(79.9\%) & $112(87.5 \%)$ & 255(83.1\%) & \\
\hline
\end{tabular}

Measurement data is presented as Mean $\pm \mathrm{SD}$ or number (\%). Group $\mathrm{P}=\mathrm{PCIA}$ only, Group TP $=$ PCIA and TAP block
Table 2 Opioid usage during perioperative period

\begin{tabular}{lllll}
\hline Opioid usage & $\begin{array}{c}\text { Group P } \\
(n=179)\end{array}$ & $\begin{array}{l}\text { Group TP } \\
(n=128)\end{array}$ & $t$ & $P$ \\
\hline Intraoperative & & & & \\
$\quad \begin{array}{l}\text { Sufentanil (ug) } \\
\quad \text { Remifentanil (mg) }\end{array}$ & $64.8 \pm 18.8$ & $51.3 \pm 12.6$ & -7.071 & $0.000^{*}$ \\
$\begin{array}{l}\text { Postoperative } \\
\quad \begin{array}{l}\text { Sufentanil usage at 24h } \\
\text { (ug) }\end{array}\end{array}$ & $45.1 \pm 30.2$ & $1.3 \pm 0.5$ & -1.831 & 0.068 \\
$\begin{array}{l}\text { Sufentanil usage at 48h } \\
\text { (ug) }\end{array}$ & $84.7 \pm 49.1$ & $90.6 \pm 50.3$ & 1.038 & 0.300 \\
\hline
\end{tabular}

Data are presented as Mean $\pm S D$, compared with Group $P,{ }^{*} P<0.05$. Group $P=$ PCIA only, Group TP = PCIA and TAP block

patients, CPSP occurred in 62 patients $(20.2 \%)$ at 3 months after surgery and 42 patients (13.7\%) at 6 months after surgery in our patients. The prevalence of CPSP was $19.5 \%(25 / 128)$ in group TP and $20.7 \%$ (37/ 179 ) in group $P$ at 3 months after surgery; $13.2 \%$ (17/ 128) patients suffered from CPSP in group TP and $13.9 \%(25 / 179)$ at 6 months after surgery. Both at 3 months and 6 months after surgery, there was no statistical difference of the prevalence of CPSP between the two groups ( 3 months, $P=0.806,6$ months, $P=0.863$, respectively) .

\section{Discussion}

Our research assumptions were partially supported. TAP block not only significantly decreased the intraoperative opioids, but also lessen pain intensity at $24 \mathrm{~h}$ and 3 months after colorectal surgery; however, such an effect did not occur at other time point.

In group TP, patients received bilateral TAP block before surgery, the NRS score both at rest and during movement at $24 \mathrm{~h}$ after surgery was significantly lower than that in group P. This result was similar to some studies, which showed that TAP block with levobupivacaine could reduce postoperative visual analogue pain scores in the first $24 \mathrm{~h}$ after major abdominal surgery, [17] and TAP block provided superior analgesia with lower pain scores at rest and movement in the first $24 \mathrm{~h}$ after colorectal surgery, when compared to PCA alone [18]. In our study, TAP block significantly decreased intraoperative sufentanil use, but there was no significant difference of sufentanil consumption at $24 \mathrm{~h}$ and $48 \mathrm{~h}$ after surgery and NRS score at $48 \mathrm{~h}$ after surgery between the two groups. Bhattacharjee et al. [19] also found that preincisional TAP block decreased intraoperative fentanyl requirements, and median time to request first postoperative analgesic was $290 \mathrm{~min}$. According to McDonnell et al. [10] and our experience, the duration of TAP was approximately 8-16 h, with complete resolution at $24 \mathrm{~h}$. Maybe this was the cause of the same 
NRS score at rest and during movement

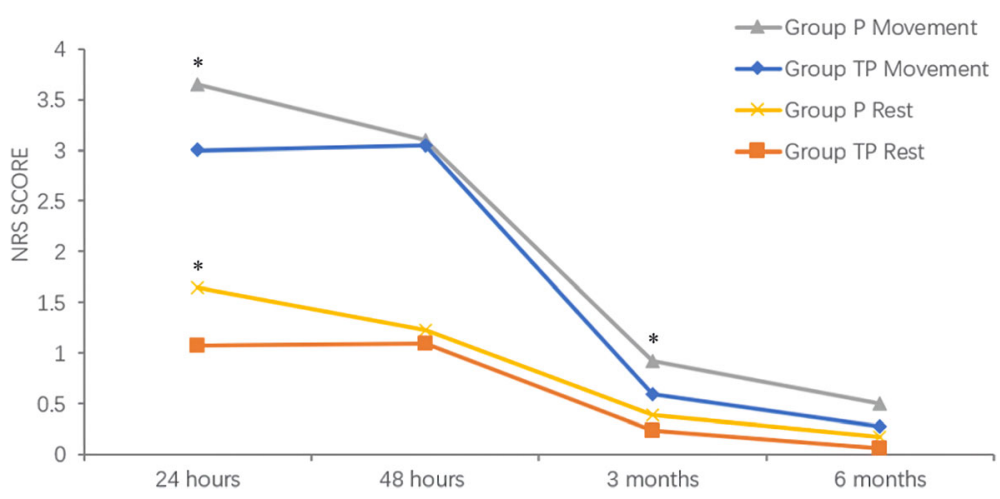

Fig. 2 NRS score at rest and during movement. Legend: The NRS score of patients at rest and during movement at different time points. Data is presented as mean \pm SD. Compared with group P, the NRS score (at rest and during movement) was decreased significantly at $24 \mathrm{~h}$ in group TP $(P<0.05)$, but there was no significant difference at $48 \mathrm{~h}$ between two groups $(P>0.05)$. In group TP, the NRS score during movement was significantly lower than that in group $P$ at 3 months after surgery $(P<0.05)$. There were no significant difference of NRS score at 6 months after surgery between two groups $(P>0.05)$. NRS = numerical rating scale. Group $P=P C I A$ only, Group TP $=P C I A$ and TAP block. * $P<0.05$

opioid consumptions at $24 \mathrm{~h}$ and $48 \mathrm{~h}$ after surgery between the two groups. All suggested that TAP block could improve acute postoperative pain and the effect lasted at most $24 \mathrm{~h}$.

In our study, the overall incidence of chronic pain was $20.2 \%$ at postoperative 3 months and $13.7 \%$ at postoperative 6 months. A prospective research documented that the prevalence of CPSP was $19 \%$ at 6 months after colorectal surgery [3]. A retrospective analysis confirmed that the prevalence of CPSP in patients with colorectal cancer was $17 \%$ at 38 months after laparoscopic colorectal surgery, [4] which was a little higher than ours at postoperative 6 months. These maybe have something to do with the difference of race and analgesia method.
However, there was no literature on how TAP block affects the incidence of CPSP in colorectal surgery. In our study, at 3 months after surgery, the prevalence of CPSP was $19.5 \%$ in group TP and $20.7 \%$ in group P; and at 6 months after surgery, the prevalence of CPSP was $13.2 \%$ in group TP and $13.9 \%$ in group P. There was no significant difference about the prevalence of CPSP between the two groups after elective colorectal surgery. Similarly, a prospective cohort follow-up study indicated TAP block did not influence the prevalence of CPSP at 6 months and 12 months after breast reconstruction [20]. A randomized controlled trial also demonstrated that TAP block did not decrease the incidence of CPSP at 6 months after cesarean delivery [21]. These told us

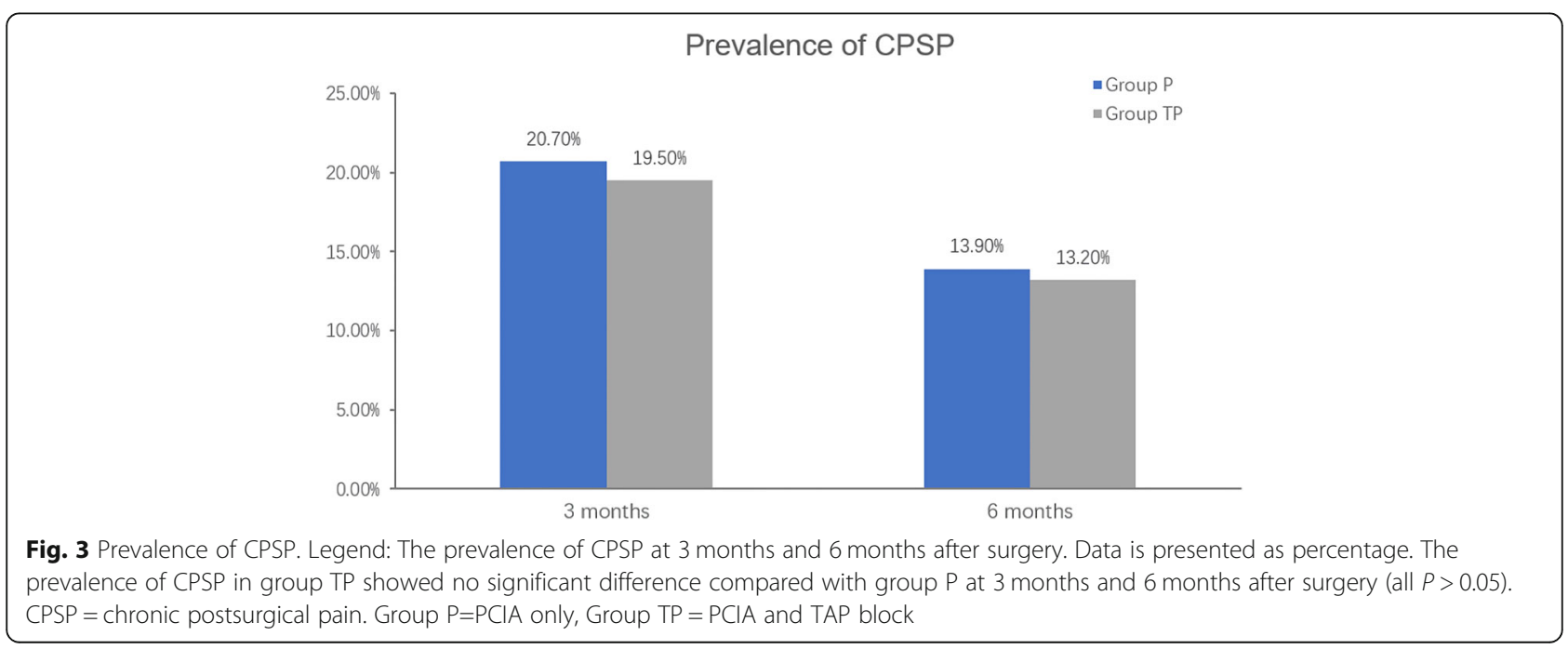


that TAP block could not decrease the incidence of CPSP.

Although TAP block did not improve the incidence of chronic pain after colorectal surgery, pain scores at 3 months was lower in group TP than that in group P, which means TAP block has positive effect on CPSP. A randomized controlled trial [14] showed that TAP block could not reduce the incidence of chronic pain after inguinal hernia repair similar to ours but they differed in reduction of the pain scores in rest and movement at 6 months.

Our study has some limitations. The design of the retrospective study made it difficult for us to strictly exclude the use of postoperative non-opioid analgesics, which may also influence postoperative pain scores. In addition, most patients in this study had been operated by the laparoscopic approach and the incidence of chronic pain was not high after intervention, which might be the cause of negative long-term results.

\section{Conclusions}

In conclusion, TAP block could relieve pain movement score at 3 months after surgery, but could not reduce the incidence of CPSP at 3 months and 6 months after selective colorectal surgery. Prospective study is required to assess the effect of TAP block on CPSP for prolonged period.

\section{Abbreviations}

TAP: Transversus abdominal plane; CPSP: Chronic postsurgical pain; PCIA: Patient controlled intravenous analgesia; NRS: Numerical rating scale

\section{Acknowledgements}

This work was supported by grant from National Key R\&D Program of China (2018YFC2001800) and by the New Xiangya talent projects of the third Xiangya hospital of Central South University. This study was also supported in part by the Research and Innovation Funds from Xiangya Big data Foundation of Central South University.

\section{Authors' contributions}

ZYP reviewed and analyzed the data and wrote the manuscript. $\mathrm{ZHH}$ guided the research and revised the manuscript. FZ contributed to the conception and design of the study. WXX aided the research, QL and YZT conceived and designed the study, and revised the manuscript for important intellectual content. All authors read and approved the final manuscript.

\section{Funding}

This work was supported by grant from National Key R\&D Program of China (2018YFC2001800) and by the New Xiangya talent projects of the third Xiangya hospital of Central South University. This study was also supported in part by the Research and Innovation Funds from Xiangya Big data Foundation of Central South University.

\section{Availability of data and materials}

The analyzed data sets generated during the study are available from the corresponding author on reasonable request.

\section{Ethics approval and consent to participate}

This study was approved by the ethics committee of the third Xiangya hospital of Central South University (2019-S473). Because of retrospective study, informed consent was waived.

\section{Consent for publication}

Not applicable.

\section{Competing interests}

The authors declare they have no competing interests.

Received: 17 December 2019 Accepted: 5 May 2020

Published online: 18 May 2020

\section{References}

1. Treede RD, Rief W, Barke A, Aziz Q, Bennett MI, Benoliel R, Cohen M, Evers S, Finnerup NB, First MB, et al. Chronic pain as a symptom or a disease: the IASP classification of chronic pain for the international classification of diseases (ICD-11). Pain. 2019;160(1):19-27.

2. Werner MU, Kongsgaard UE. Defining persistent post-surgical pain: is an update required? Br J Anaesth. 2014;113(1):1-4.

3. Deiss T, Chen LL, Sarin A, Naidu RK. Patient-reported outcomes 6 months after enhanced recovery after colorectal surgery. Perioper Med (Lond). 2018;7:19.

4. Joris JL, Georges MJ, Medjahed K, Ledoux D, Damilot G, Ramquet CC, Coimbra Cl, Kohnen LP, Brichant JF. Prevalence, characteristics and risk factors of chronic postsurgical pain after laparoscopic colorectal surgery: retrospective analysis. Eur J Anaesthesiol. 2015;32(10):712-7.

5. Kehlet $\mathrm{H}$, Jensen TS, Woolf CJ. Persistent postsurgical pain: risk factors and prevention. Lancet. 2006;367(9522):1618-25.

6. Glare P, Aubrey KR, Myles PS. Transition from acute to chronic pain after surgery. Lancet. 2019;393(10180):1537-46.

7. Carroll I, Hah J, Mackey S, Ottestad E, Kong JT, Lahidji S, Tawfik V, Younger J, Curtin C. Perioperative interventions to reduce chronic postsurgical pain. J Reconstr Microsurg. 2013:29(4):213-22.

8. Andreae $\mathrm{MH}$, Andreae DA. Regional anaesthesia to prevent chronic pain after surgery: a Cochrane systematic review and meta-analysis. $\mathrm{Br} J$ Anaesth. 2013;111(5):711-20.

9. Bouman EA, Theunissen M, Bons SA, van Mook WN, Gramke HF, van Kleef M, Marcus MA. Reduced incidence of chronic postsurgical pain after epidural analgesia for abdominal surgery. Pain Pract. 2014;14(2):E76-84.

10. McDonnell JG, O'Donnell B, Curley G, Heffernan A, Power C, Laffey JG. The analgesic efficacy of transversus abdominis plane block after abdominal surgery: a prospective randomized controlled trial. Anesth Analg. 2007; 104(1):193-7.

11. McDonnell JG, O'Donnell BD, Farrell T, Gough N, Tuite D, Power C, Laffey JG. Transversus abdominis plane block: a cadaveric and radiological evaluation. Reg Anesth Pain Med. 2007;32(5):399-404.

12. Conaghan P, Maxwell-Armstrong C, Bedforth N, Gornall C, Baxendale B, Hong $\mathrm{LL}$, Carty HM, Acheson AG. Efficacy of transversus abdominis plane blocks in laparoscopic colorectal resections. Surg Endosc. 2010;24(10):2480-4.

13. Siddiqui MR, Sajid MS, Uncles DR, Cheek L, Baig MK. A meta-analysis on the clinical effectiveness of transversus abdominis plane block. J Clin Anesth. 2011;23(1):7-14.

14. Theodoraki K, Papacharalampous P, Tsaroucha A, Vezakis A, Argyra E: The effect of transversus abdominis plane block on acute and chronic pain after inguinal hernia repair. A randomized controlled trial. Int J Surg 2019, 63:63-70.

15. Liu L, Xie YH, Zhang W, Chai XQ. Effect of Transversus Abdominis plane block on postoperative pain after colorectal surgery: a meta-analysis of randomized controlled trials. Med Princ Pract. 2018;27(2):158-65.

16. Kanazi GE, Aouad MT, Abdallah FW, Khatib MI, Adham AM, Harfoush DW, Siddik-Sayyid SM. The analgesic efficacy of subarachnoid morphine in comparison with ultrasound-guided transversus abdominis plane block after cesarean delivery: a randomized controlled trial. Anesth Analg. 2010;111(2): 475-81.

17. Saxena A, Bansal R, Mittal A, Shrivastava U. Sharma P, chand T: evaluation of postoperative analgesic efficacy of transversus abdominis plane block after abdominal surgery: a comparative study. J Nat Sci Biol Med. 2013:4(1):177-80.

18. Bharti N, Kumar P, Bala I, Gupta V. The efficacy of a novel approach to transversus abdominis plane block for postoperative analgesia after colorectal surgery. Anesth Analg. 2011;112(6):1504-8.

19. Bhattacharjee S, Ray M, Ghose T, Maitra S, Layek A. Analgesic efficacy of transversus abdominis plane block in providing effective perioperative analgesia in patients undergoing total abdominal hysterectomy: a randomized controlled trial. J Anaesthesiol Clin Pharmacol. 2014;30(3):391-6.

20. Justin O, M PG, Toni Z, Stuart M, Coimbatore S, C ONA, James K, Joel K, P $\mathrm{HSO}$, Hance C. Chronic postsurgical pain outcomes in breast reconstruction patients receiving perioperative Transversus Abdominis plane catheters at the donor site: a prospective cohort follow-up study. Pain Pract. 2016:17(8): 999-1007. 
21. Mckeen DM, George RB, Boyd JC, Allen VM, Pink A. Transversus abdominis plane block does not improve early or late pain outcomes after cesarean delivery: a randomized controlled trial. Can J Anaesth. 2014;61(7):631-40.

\section{Publisher's Note}

Springer Nature remains neutral with regard to jurisdictional claims in published maps and institutional affiliations.

Ready to submit your research? Choose BMC and benefit from:

- fast, convenient online submission

- thorough peer review by experienced researchers in your field

- rapid publication on acceptance

- support for research data, including large and complex data types

- gold Open Access which fosters wider collaboration and increased citations

- maximum visibility for your research: over $100 \mathrm{M}$ website views per year

At $B M C$, research is always in progress.

Learn more biomedcentral.com/submissions 